\title{
The Dependency of Engineering Technology Student's towards the Usage of Calculator in Mathematics
}

\author{
Nor Hafizah Hussin ${ }^{1, a}$, Siti Haryanti Hairol Anuar ${ }^{1}$, Khairum Hamzah ${ }^{1}$, Mohd Fariduddin Mukhtar ${ }^{1}$ and Irianto $^{1}$ \\ ${ }^{1}$ Faculty of Engineering Technology, Universiti Teknikal Malaysia Melaka, Hang Tuah Jaya, 76100 Durian Tunggal, Melaka, Malaysia
}

\begin{abstract}
Calculators are one of the important technology used to solve mathematical computations. It also can be the tool for learning mathematics if it is used appropriately. However, too much depends on calculator can be harmful to students ability to solve simple mathematical problem. The purpose of this study is to examine the dependency of students in Faculty of Engineering Technology (FTK), Universiti Teknikal Malaysia Melaka, on the usage of calculator to solve the mathematical problems. A sample of 383 first year Engineering Technology (ET) students' taking mathematics subject are selected from five different course. Students were examined based on the results of Mathematic Competency Test and the survey from a questionnaire that covers questions regarding the students' enjoyment on the usage of calculator and the usefulness of calculator in mathematic activities. The investigation yield a result showing that the students has a high dependency on using calculator to solve mathematical problem.
\end{abstract}

\section{Introduction}

Mathematics is a subject that involves calculation and the calculating device have existed for thousands of years ago. Calculator is one of a calculating device used for so many years and has evolved dramatically for every new generation. It is known to be the best tools to aid mathematics learning because it allows the students to access the mathematical concepts and experiences from which they were previously limited with only paper and pencil [1]. Calculator is also proven to be the tools to help increase the effectiveness of learning mathematics. Few researchers have examined the attitudes of students towards calculator and the effect of calculator towards the students' achievement in mathematics. It is proven that the use of calculator resulted in better students' attitude thus enhances students' mathematic self-concept and maintain their motivation to learn [2].

Calculator helps to solve simple and complicated mathematics computation. To solve mathematical problem, students' need to apply their mathematics knowledge before using calculator to do the calculation. Despite all the capabalities and benefits, calculators can never replace the human capabilities in solving mathematics. It does not helps in understanding the problem, choosing the equation to solve the problem and finding the correct answer. Calculator will only be helpful when the student feed the information to it. However, students' nowaday are still using calculator even if it is just a simple mathematical problem. This is because, according to findings in [3], majority of the students' enjoy using calculator and considered mathematics to be easier when a calculator is used to solve problems. This shows that the students' has a high dependency towards calculator. The study in [4] indicates that it is vital that students' gain proficiency in basic skills before being allowed access to technology which can short-cut their understanding. Calculator helps students to access the lesson very quickly, however, it also can hinder students' ability to focus on problem solving methods.

The objective of this study is to examine the dependency of engineering technology (ET) students' in Faculty of Engineering Technology (FTK), Universiti Teknikal Malaysia Melaka, towards the usage of calculator for solving mathematical problem. ET is a field of applied physics that focus on applying knowledge in physics to solve technical problems. On the other hand, mathematics is the language of physics and it is use widely in this subject. Hence, in order for the students to pursue their studies in ET undergraduate course, they are required to be proficient in mathematics [6]. Mathematics is an important subject for the ET students because it has a high relationship with ET field. Students who took ET course will use a lot of mathematical concept in their study. Hence, it is important for the students to enhance their knowledge of concept in algebra, trigonometry, calculus and statistics.

According to [7], ET program is one of the new education field in Malaysia and was first offered by a public university in June 2011, which is Universiti Teknikal Malaysia Melaka (UTeM). Students that entered this program came from three type of programs from post-secondary education institutions which are Matriculation, Malaysia Higher School Certificate (STPM), and Diploma. Mathematics is a core subject for

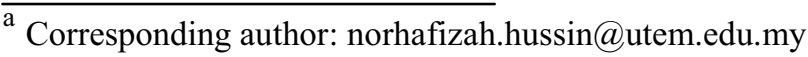


these three programs and all the students are required to pass the subject for completion [8],[9]. Through out the sessions, students are able to use the calculator to aid the learning process as well as during the examination. The student has been exposed to the calculator since the secondary school level and have been using it in higher level institutions. This will some how effect their skills on solving basic mathematics question without using a calculator. The objective of this study is to examine the dependency of the first year ET students' towards calculator for solving mathematics by comparing the results of their mathematics competency test with an analysis from a survey.

\section{Methodology}

Three hundred-eighty three first year ET students' in FTK, UTeM from five different course were involved in this study. The Mathematic Competency test is a test for all new first year students in University Teknikal Malaysia Melaka (UTeM). The main purpose of this test is to measure the students background in mathematics such as the knowledge as well as the competency of the students when entering UTeM. Besides that, it helps to acknowledge the lecturers about the students level of understanding so that the subject can be carried out smoothly. This test consist of 40 fundamental questions that divided into two subtopics which is algebra and calculus. During the test, students are not allowed to use a calculator. This test is conducted in semester one for the $2015 / 2016$ session and the students need to answer all the questions without using a calculator.

A set of questionnaire obtained from [10] were given to the student to assess their attitudes towards the usage of calculator focusing on the dependency of students on using calculator to solve mathematics problem. The questionnaire consist of two parts which is the enjoyment when using calculator and the usefulness of calculator in learning mathematics. According to [10], the term enjoyment is referred to as whether students liked using calculators during mathematics. The questions are as follows:

i. I enjoy using a calculator in mathematics activities

ii. A calculator is interesting, fascinating and easy to use

iii. enjoy investigating mathematics problems using a calculator

iv. A calculator is very interesting and challenging to use

The term usefulness in [10] is referred to as whether students viewed calculator as helpful tools in learning mathematics. The questions are as follows:

i. I do not have any use for calculators on a day to day basis

ii. I do not think a calculator will be useful to me in my future job

iii. I do not see how a calculator can help me to learn some new skills.

iv. Anything that a calculator can be used for, I can do just as well some other way.
All 383 students answer the test and questionnaire successfully. These results were analyzed using Microsoft Excel to obtain the statistical results for each of the questions.

\section{Result and Discussion}

The purpose of this study is to examine the dependency of first year ET students' in FTK on the usage of calculator to solve mathematical problem. The author compares the result from the mathematics competency test and result from the questionnaire to examine the dependency. Table 1 below shows the result for mathematic competency test for the selected first year ET students' from electric, electronic, mechanical and manufacturing students under the Bachelor of Engineering Technology program in FTK, UTeM.

Table 1. Students' results for Mathematic Competency Test.

\begin{tabular}{|c|c|c|c|c|}
\hline \multirow[b]{2}{*}{$\begin{array}{l}\text { No. of } \\
\text { student }\end{array}$} & \multirow[b]{2}{*}{$\begin{array}{c}\text { Average } \\
\text { Marks }\end{array}$} & \multirow[b]{2}{*}{$\begin{array}{l}\text { Standard } \\
\text { Deviation }\end{array}$} & \multicolumn{2}{|c|}{ No. of students } \\
\hline & & & $\begin{array}{c}\text { Less } \\
\text { than } \\
20 \\
\text { marks }\end{array}$ & $\begin{array}{c}\text { More } \\
\text { than } \\
20 \\
\text { marks }\end{array}$ \\
\hline 383 & 7.11 & 1.19 & 365 & 18 \\
\hline
\end{tabular}

The results listed in Table 1 above shows that the students did not perform during the test yielding an average marks of only 7.11 over 40 . Among the 383 students selected, only 18 students get a mark higher that 20 showing that only $4.7 \%$ of the students perform during the test. The standard deviation measures the dispersion of the data. A small standard deviation indicates that the data points tend to be close to the mean while a large standard deviation indicates that the data points are spread out over a wider range of values. Based on the results in Table 1, a small value of the standard deviation which is 1.19 indicates that the data points tend to be close to the average marks. This shows that among the 383 students selected, most of them get a marks around the average marks which is 7.11 out of 40 , proving that the students did not perform well during the test.

Based on this results, the lecturer in FTK come out with a hypothesis that the students cannot answer the question due to the restriction of using calculator during the test because students nowadays prefer to use calculator to solve mathematics problem. To prove that the lecturer's claim is true, a set of questionnaire was designed to assess student's perception towards calculator for solving mathematical problem. Generally, most of the respondents agree that they prefer to use calculator to solve mathematics problem, as shown in Table 2.

The majority of the students, which is, $88.8 \%$ agree that they enjoy using calculator in mathematics activities. 334 out of 383 respondents, which is $87.2 \%$ agree that learning and solving mathematics will be more enjoyable with the use of calculator and $86.9 \%$ of the students enjoy investigating mathematics problem using calculator. 
$81.3 \%$ of the students agree that calculator is very interesting to use especially when it comes to solving a mathematical problems. These statements shows that the students enjoy using calculator in learning and solving mathematics. Hence, we can see the dependency among the students towards the usage of calculator in solving mathematic problems.

Table 2. Students' Enjoyment of Using Calculator.

\begin{tabular}{|c|c|c|}
\hline \multirow{2}{*}{ Statement } & \multicolumn{2}{|c|}{ Percentage (\%) } \\
\cline { 2 - 3 } & Agree & Disagree \\
\hline $\begin{array}{c}\text { I enjoy using a calculator in } \\
\text { mathematics activities }\end{array}$ & 88.8 & 11.2 \\
\hline $\begin{array}{c}\text { A calculator is interesting, } \\
\text { fascinating and easy to use }\end{array}$ & 87.2 & 12.8 \\
\hline $\begin{array}{c}\text { I enjoy investigating mathematics } \\
\text { problems using a calculator }\end{array}$ & 86.9 & 13.1 \\
\hline $\begin{array}{c}\text { A calculator is very interesting } \\
\text { and challenging to use }\end{array}$ & 81.3 & 18.7 \\
\hline
\end{tabular}

Table 3. Students' Perception on the Usefulness of Calculator.

\begin{tabular}{|c|c|c|}
\hline \multirow{2}{*}{ STATEMENT } & \multicolumn{2}{|c|}{$\begin{array}{c}\text { PERCENTAGE } \\
\text { (\%) }\end{array}$} \\
\cline { 2 - 3 } & Agree & Disagree \\
\hline $\begin{array}{c}\text { I do not have any use for } \\
\text { calculators on a day to day basis }\end{array}$ & 20.8 & 79.2 \\
\hline $\begin{array}{c}\text { I do not think a calculator will } \\
\text { be useful to me in my future job }\end{array}$ & 18.2 & 81.8 \\
\hline $\begin{array}{c}\text { I do not see how a calculator } \\
\text { can help me to learn some new } \\
\text { skills. }\end{array}$ & 25.1 & 74.9 \\
\hline $\begin{array}{c}\text { Anything that a calculator can } \\
\text { be used for, I can do just as well } \\
\text { some other way }\end{array}$ & 58.1 & 41.9 \\
\hline
\end{tabular}

Result from Table 3 above shows that most of the students agree that the calculator is useful in mathematics as well as their daily basis. Among 383 students, only $20.8 \%$ agree that calulator do not have any use in daily basis. It shows that most of the students think that besides using calculator to solve mathematic problems, calculator also helps them in other field. $81.8 \%$ of the students disagree with the statement that they do not think a calculator will be useful for their future job. This shows that the calculator will be useful to them not only in learning mathematics, but also in the future undertaking. $74.9 \%$ disagree with the statement that calculator in not helping in learning some new skills shows that the students think that they can also learn new skills using calculator because some of the mathematics problem can solve straight away from the calculator.

Based on the result obtained in Table 1, Table 2 and Table 3, we can say that the ET students' in FTK really depends on calculator when solving mathematics problem and the fact that they need to answer the mathematics competency test without using calculator makes them feel uncomfortable and not confident to anwer the question.
This factors then affect the students marks for Mathematic Competency test as shown in Table 1.

\section{Conclusion}

The finding of this investigation shows that the calculator plays an important role to the students approach in learning and solving mathematics. The main focus of this study is to investigate the dependency of first year ET students' in solving mathematics using calculator. Hence, the result of this study supported the authors claims proving that the first year ET students' in FTK, UTeM have a high dependency on using calculator to solve mathematical problems. The calculator can be a tool to motivate the students to enjoy learning mathemathics especially in solving complicated problems. However, a high dependency on the calculator will limit the students ability to solve simple and basic mathematical problems. An inferential statistics may also be perform for future study, which is by making a hypothesis testing about the dependency of the students towards the calculator by comparing the data from the new first year ET students' in FTK with the existing data. Making a hypothesis testing about this will helps to prove whether or not the first year ET students' in FTK really depends on calculator when it comes to solving a mathematical problems. The results of this study must be interpreted with caution as it is only consist of first year ET students. For future study, a larger sample size should be considered so that a stronger conclusion can be made about the dependency of the first year ET students' in FTK towards calculator in solving mathematics.

\section{Acknowledgement}

All the authors acknowledge support from the Faculty of Engineering Technology (FTK), Universiti Teknikal Malaysia Melaka (UTeM) and those who are in help with the ideas and distribution of mathematics competency test and mini survey.

\section{References}

1. H. Pomeratz. Prepared for the Urban Systemic Initiative/Comprehensive Partnership for Mathematics and Science Achievement (USI/CPMSA). Superintendents Forum. Dallas, Texas. (1997)

2. A. J. Ellington, Journal for Research in Mathematics Education. 34(5), 433-463 (2003)

3. L. Avernon and J. Bobis. University of Sydney. (1995)

4. Z. K. Mbugua, M. W. Muthomi, and M. O. Okere. Int. Journal of Humanities and Social Science. 1(13), 131-136 (2011)

5. J. Clark. Research Paper. SUNY Oswego (2011)

6. E. Goold. . Paper Presented at $41^{\text {st }}$ SEFI Conference. Leuven, Belgium. (2013) 
7. M. S. Yahaya, A. Noordin, S. Ahmad, and M. R. Sapiee. Proc. International Conference on Teaching and Learning in Higher Education, Johor, Malaysia. (2012)

8. N. Misran, S. N. S. Sahuri, S. Arsad, H. Hussain, W. M. D. W. Zaki, and N. A. Aziz. Asian Social Science. 8(16), 222-231 (2012)

9. M. Alias. (Doctoral Dissertation). Retrieved from https://core.ac.uk/download/files/434/12007833.pdf (2012)

10. L. M. Kaino and E. B. Salani. In Proceedings of the $28^{\text {th }}$ Conference of International. 3, 113-120. (2004) 